\title{
Entre o fundamental e o contingente: dimensões da gentrificação contemporânea nas operações urbanas em São Paulo*
}

\author{
Between the fundamental and the contingent: dimensions \\ of contemporary gentrification in urban operations in São Paulo
}

Marina Toneli Siqueira

\begin{abstract}
Resumo
Opondo-se à importação direta de teorias, este artigo desenvolve um modelo analítico para o estudo da gentrificação que abarca tanto sua generalização como principal política do urbanismo neoliberal quanto sua localização em contextos urbanos específicos. 0 modelo analítico baseia-se em três dimensões necessárias e definidoras do processo: 1) produção do espaço gentrificável; 2) elitização social com expulsão de grupos vulneráveis; e, 3) transformação da paisagem construída. 0 estudo das operações urbanas em São Paulo demonstra que estas dimensões fundamentais são mediadas por estruturas locais e, nestes casos, contextualizadas em projetos urbanísticos individuais. Este artigo, portanto, explora as múltiplas escalas de promoção da gentrificação, enfatizando que formas de produção desigual do espaço e resistência às mesmas também são produzidas localmente.
\end{abstract}

Palavras-chave: gentrificação; neoliberalismo; pós-modernidade; operações urbanas; São Paulo.

\begin{abstract}
Opposing the direct importation of theories, this paper develops an analytical model for the study of gentrification that encompasses both its generalization as the main policy of neoliberal urbanism and its location in specific urban contexts. This analytical model is based on three necessary dimensions that define the process: 1) production of gentrifiable space; 2) socio-economic upgrading with displacement of vulnerable groups; 3) built landscape transformation. The study of urban operations in São Paulo demonstrates that these fundamental dimensions are mediated by local structures and, in these cases, they are contextualized in individualized urban projects. This paper, thus, explores the multiple scales of gentrification promotion, and emphasizes that forms of unequal space production and resistance to them are also locally produced.
\end{abstract}

Keywords: gentrification; neoliberalism; postmodernity; urban operations; São Paulo. 


\section{Introdução}

Gentrificação não é um conceito desconhecido no Brasil. De fato, a própria presença deste volume demonstra a sua crescente inserção nos estudos urbanos brasileiros. 0 conceito tem sido utilizado na sua acepção original em inglês (gentrification), no seu neologismo (gentrificação) ou tem sido traduzido em construções linguísticas que enfatizam a transformação socioeconômica característica do processo (enobrecimento urbano). Entretanto, grande parte destes estudos não tem lidado diretamente com os problemas teóricos decorrentes da importação do conceito para explicar um contexto urbano diferente daquele no qual ele foi originado. Por outro lado, mesmo nos contextos originais ou nos casos clássicos de gentrificação na Inglaterra e nos Estados Unidos, a teoria tem gerado acirrado debate sobre sua aplicabilidade. Neste sentido, argumenta-se que a sua expansão ou generalização teria conduzido à falta de precisão conceitual. Este artigo, entretanto, enfatiza a necessidade de contextualizar o nosso entendimento sobre gentrificação, considerando que a interação entre padrões locais e globais pode alterar o processo temporal e espacialmente. Desta forma, realiza-se uma defesa do conceito de gentrificação sem perder de vista a necessidade de elaborar um modelo de análise que seja ao mesmo tempo rigoroso e flexível. Isto é, trata-se de um esforço para que o mesmo não perca sua capacidade analítica, mas que também auxilie a explicar dados empíricos que podem ser contextuais e específicos.

Este artigo tem como objetivo, portanto, desenvolver um modelo analítico para o estudo de processos de gentrificação, utilizando como caso ilustrativo de sua aplicabilidade as operações urbanas em São Paulo. Gentrificação, de forma geral, é definida como o processo de redesenvolvimento urbano que acarreta na elitização socioespacial. Indo de encontro à importação direta de teorias, argumenta-se que existem dimensões necessárias e definidoras do processo que não são, todavia, suficientes para compreender o seu funcionamento em cada contexto urbano. Portanto, embora elementos fundamentais estejam presentes em todos os casos de gentrificação, ainda existem dimensões contingentes (ou estruturas mediadoras) que explicam as diferenças que ocorrem localmente. Neste sentido, na primeira parte deste artigo serão discutidas as dificuldades do uso da teoria clássica da gentrificação no contexto brasileiro. Em especial, será demonstrado como, por um lado, os casos brasileiros têm desafiado uma definição restritiva do conceito enquanto, por outro lado, os estudos urbanos fora do país tem expandido a teoria para considerar transformações do processo. Na segunda parte, será desenvolvida uma definição da gentrificação contemporânea que a inclui nas estratégias do urbanismo neoliberal e na experiência urbana pós-moderna. De forma a ilustrar este modelo analítico, na terceira e quarta partes aqueles elementos necessários e definidores do processo serão explorados tendo em vista a principal política brasileira de redesenvolvimento urbano, as Operações Urbanas Consorciadas. ${ }^{1}$ As operações urbanas foram escolhidas como ilustrativas da generalização de parcerias público-privadas para a valorização do solo urbano. Ao mesmo tempo, elas demonstram que aquelas dimensões fundamentais da gentrificação (se presentes) serão mediadas nacionalmente pela formalização do instrumento através do 
Estatuto da Cidade e localmente em um projeto específico, constituindo não somente um lugar próprio (i.e., uma geografia urbana), mas também parâmetros urbanísticos diferenciados para cada experiência. Dessa forma, a escolha do caso leva em consideração que nem mesmo entre as operações urbanas o processo de gentrificação pode ser homogêneo. Isto sugere, portanto, que embora o modelo analítico possa e deva ser generalizado para outros casos, os achados empíricos sobre uma operação urbana em particular podem não o ser.

\section{A expansão do conceito: divergências entre a teoria clássica e os casos brasileiros}

Desde 1964, quando Ruth Glass cunhou o conceito para a análise de processos de sucessão residencial e expulsão de grupos vulneráveis em bairros centrais de Londres (Glass, 2010 [1964]), gentrificação tem sido objeto de intensa produção acadêmica, sendo reconhecida por muitos pesquisadores como "um dos mais importantes vetores da reestruturação urbana contemporânea" (Hamnett, 1991, p. 174). ${ }^{2}$ Esta intensa produção acadêmica, todavia, tem gerado uma preocupação com a própria definição e uso do conceito. 0 debate divide-se entre uma definição original e mais restritiva - a transformação de unidades residenciais através de reformas feitas por novos moradores de um padrão socioeconômico mais elevado (Glass, 1989; Lambert e Boddy, 2002) - e uma percepção contemporânea e mais abrangente do processo que inclui usos, agentes e formas de intervenção espacial diversas, como estudos sobre gentrificação comercial (Chernoff, 1980), gentrificação turística (Gotham, 2005) e gentrificação global (Smith, 2002; Atkinson e Bridge, 2005). Considerando esta expansão do conceito para entender novas formas e casos internacionais, autores - incluindo a própria Glass (1989) - acreditam que gentrificação tornou-se um conceito caótico ao abarcar processos de produção do espaço muito diversos em um único termo universalista e abrangente. Sugere-se inclusive o abandono completo do termo, em vista de sua trivialização e incompatibilidade com estes novos casos, incluindo aqueles em cidades brasileiras. É nesse sentido que autores irão defender a utilização de termos alternativos, como reurbanização (Lambert e Boddy, 2002). Este artigo, entretanto, faz uma defesa do conceito considerando seu caráter eminentemente político, uma vez que se relaciona à produção do espaço, exclusão socioespacial e intersecção de interesses públicos e privados. Enquanto as cidades têm passado por intensas transformações políticas, econômicas e socioculturais desde a primeira utilização do conceito, aquela definição mais restritiva possui uma capacidade explicativa reduzida para compreender os processos urbanos contemporâneos e é importante levar em consideração a evolução do processo tanto nos contextos urbanos originais quanto nos casos mais recentes. É nesse sentido, portanto, que se pode abordar as dificuldades na importação direta da teoria clássica da gentrificação para explicar casos no Brasil.

Inspirado nas experiências da Inglaterra e Estados Unidos, o uso acadêmico inicial do conceito está ligado à identificação de um fenômeno original no desenvolvimento urbano local daqueles países - i.e., a reversão do 
histórico processo de suburbanização. Na sua acepção original, a teoria da gentrificação explora o movimento de capital (e pessoas) deixando os bairros urbanos em direção aos subúrbios e o seu posterior retorno com a possibilidade de extração de mais-valias das áreas que sofreram desinvestimento. Neste sentido, o capital - público e privado - foi desviado das cidades para os subúrbios, em especial no período pós-guerras mundiais considerando as maiores possibilidades de lucro (Hall, 2002; Harvey, 1989b; Smith, 1996 e 2010b). A falta de investimento nos bairros urbanos, por outro lado, transformou-os em uma opção habitacional para grupos empobrecidos, estabelecendo uma defasagem entre as potencialidades de extração de mais-valias do solo urbano se os mesmos fossem redesenvolvidos para um possível uso "melhor e mais valorizado", i.e., um gap imobiliário (Smith, 2010b). Existe, portanto, um padrão de desinvestimento que fez com que o processo de gentrificação seja possível, uma vez que o reinvestimento com mudança de usos e usuários seria a fonte dos lucros potenciais. Ademais, enquanto as elites econômicas e sociais são beneficiárias em todas as etapas deste processo (tanto da suburbanização quanto da gentrificação), os custos recaem sobre os grupos mais vulneráveis, com a expulsão de comunidades de baixa renda e minorias étnicas e raciais.

Entretanto, é importante considerar que diferentes modelos de desenvolvimento urbano, como cidades na Europa continental, não seguem o mesmo padrão de desinvestimento, uma vez que essas cidades são historicamente densas e com bairros centrais de alto valor agregado do solo urbano. De certa forma, este é o caso de várias cidades brasileiras, inclusive de São Paulo. Embora essa tenha experimentado um processo de relativo esvaziamento de seu centro histórico, a capital paulista continua atingindo altas densidades e valores das propriedades no centro expandido com a população de baixa renda sendo historicamente expulsa para as periferias (Rolnik, 1997; Villaça, 1998). Portanto, originada a partir de um processo indutivo de análise da mudança do padrão de desenvolvimento urbano na Inglaterra e nos Estados Unidos, a teoria da gentrificação não consegue explicar por inteiro a produção do espaço gentrificado em contextos urbanos que não vivenciaram um padrão tão claro de desinvestimento. Mais do que um movimento de "retorno de capital para as cidades" (Smith, 2010b), a análise desses processos deve considerar os ciclos do capital que geram mais-valias diferenciadas no tempo e no espaço, constituindo geografias de investimento e desinvestimento e, consequentemente, a possibilidade de gentrificação. Dessa forma, ao invés de estar ligado a um único tipo de localização (centros urbanos), a gentrificação está conectada a processos mais abrangentes de produção do espaço que podem se dar em diferentes configurações e localizações urbanas.

Um segundo aspecto que casos no Brasil divergem da teoria clássica da gentrificação está relacionado às condições do ambiente construído. Considerando as transformações nos usos e usuários, é difícil identificar um caso no qual o ambiente construído não seja uma dimensão fundamental do processo. Já nos primeiros estudos sobre gentrificação, inclusive em Glass (2010 [1964]), a arquitetura dos bairros gentrificados era um elemento importante do processo. Isso porque naquele período os edifícios históricos passaram por um processo 
de revalorização em contraste com o que é assumido como uma arquitetura homogeneizante do período moderno. Assim, a gentrificação deve ser entendida também dentro da transformação da modernidade para a pós-modernidade tanto no sentido das demandas por mais liberdades individuais e socioculturais, bem como na valorização de modos de vida urbanos, em contraste direto com o intenso processo de suburbanização anterior. Portanto, não é por coincidência que muitos dos casos clássicos de gentrificação têm uma configuração socioespacial parecida com aquela defendida por Jacobs (1992 [1961]) em um dos principais livros da crítica à arquitetura e ao urbanismo modernistas. Por outro lado, esse processo de valorização de arquiteturas históricas e bairros centrais não significa o congelamento de suas condições físicas. Pelo contrário, mesmo nos bairros onde as estruturas físicas são o maior atrativo para grupos gentrificadores - por exemplo, as tradicionais Brownstones e edifícios industriais nos casos clássicos em Nova York - existe um processo de modificação do espaço construído por meio de reformas, renovações e melhorias de serviços públicos e privados. Essa transformação física acontece tanto por causa do desinvestimento anterior, quanto por causa dos distintos padrões de consumo e reprodução social entre antigos e novos usuários.

Utilizando como paralelo os casos clássicos de gentrificação, a maioria dos estudos sobre o processo no Brasil tem focado em projetos de "revitalização" 3 dos centros históricos brasileiros (e.g., Frúgoli Jr. e Sklair, 2008; Leite, 2007; Rubino, 2005; Vargas e Castillo, 2005). A análise explora a privatização e comercialização do patrimônio histórico após um período de desinvestimento no qual atividades econômicas foram direcionadas para outras áreas urbanas, como no processo de formação de novas centralidades em São Paulo (Frúgoli Jr., 2000). Entretanto, se projetos de "revitalização" têm causado gentrificação nos Estados Unidos e Europa (Bidou-Zachariansen, 2006; Harvey, 1997, 1989c), no Brasil os resultados são menos claros. Autores têm demonstrado que os projetos de "revitalização" não têm resultado em uma transformação efetiva dessas áreas em termos residenciais, sendo o impacto pequeno, pouco duradouro ou restrito às quadras adjacentes aos projetos-âncora (Leite, 2007). Intervenções pontuais, financiadas em especial pelo Estado através da promoção de distritos culturais e instalações turísticas, têm promovido uma gentrificação do consumo (Frúgoli Jr. e Sklair, 2008) que é limitada a espaços e períodos específicos, sem transformar drasticamente a paisagem socioeconômica dessas áreas. Portanto, é possível identificar uma estratégia de intervenção que objetiva a gentrificação enquanto sua falha em alcançá-la pode ser causada, em especial, pela falta de interesse dos grupos de renda mais alta por opções de moradia nos centros históricos (Silva, 2006). Mesmo assim, ao considerarmos que a maior parte desses estudos brasileiros utiliza a definição clássica do conceito, calcada na reversão da suburbanização e valorização de bairros históricos, é importante explorar outras formas de transformação do ambiente construído que a gentrificação pode causar, levando em consideração geografias de investimento e desinvestimento mais condizentes com o padrão de urbanização brasileiro, como mencionado anteriormente. Propõe-se então a aplicação do conceito para o estudo de transformações socioespaciais com novas construções. 
Uma vez que gentrificação tornou-se um "produto baseado no lugar" (Zukin, 1987, p. 193), a evolução do processo pode incluir sua localização em geografias que induzem a novos tipos de transformação do ambiente construído, desde reformas e renovações até novas construções e verticalização (Davidson e Lees, 2010). Se em seus primeiros estudos Smith (2010a [1982]) identificava uma diferença entre gentrificação e redesenvolvimento urbano - o primeiro relacionado a reformas de edifícios históricos e o segundo envolvendo novas edificações -, em análises mais recentes (em especial Smith, 2002) o autor reconhece que essa diferença é irreal, uma vez que os dois tipos de transformação do ambiente construído podem causar elitização social. Finalmente, a gentrificação com demolições e novas construções também pode ser caracterizada por um envolvimento de agentes mais diversos no planejamento, marketing e venda desses espaços, como arquitetos, construtoras e incorporadoras, bem como um papel mais intenso do Estado (Davidson e Lees, 2005; Hackworth, 2006; Hackworth e Smith, 2001). Entretanto, certos estudos urbanos têm resistido em considerar o Estado como agente promotor da gentrificação.

Uma outra divergência entre os estudos brasileiros sobre gentrificação e os casos tradicionais é identificada na presença do Estado como agente condutor do processo em contraste com o que é assumido como uma iniciativa do mercado imobiliário (especialmente em Frúgoli Jr. e Sklair, 2008). Primeiramente, é importante mencionar que gentrificação pressupõe tanto agentes privados quanto públicos já nas análises de casos mais tradicionais, uma vez que o processo não iria acontecer sem o suporte e o apoio do Estado - e.g., no direcionamento de investimentos, estímulos ao redesenvolvimento e suporte à remoção de residentes. Entretanto, considerando os primeiros desenvolvimentos teóricos na Inglaterra e Estados Unidos, existia uma diferença nos agentes envolvidos nos processos de gentrificação e no período de renovação urbana nas décadas de 1950 e 1960 (Hall, 2002). Para esse tipo de abordagem, durante o período de renovação urbana o Estado seria o promotor do processo que poderia gerar a elitização urbana, enquanto na gentrificação ele seria apenas o facilitador do reinvestimento privado na área. Os debates teóricos recentes, entretanto, têm chamado atenção para o entendimento das relações entre políticas públicas e gentrificação (Hackworth e Smith, 2001; Lees, 2000; Smith, 2002). Em um contexto de expansão do urbanismo neoliberal, a gentrificação tem sido associada com a mudança do gerenciamento para o empresariamento urbano (Harvey, 1989c), transformando-se em uma "parte ativa das políticas públicas" (Lees e Ley, 2008, p. 2379). No entanto, é importante notar que o termo gentrificação não é utilizado em leis ou documentos oficiais tanto nos casos tradicionais quanto nos contextos recentes, inclusive no Brasil. Ao invés de gentrificação, termos velados - e.g., regeneração, revitalização e reurbanização - são utilizados para despolitizar a questão da elitização socioeconômica e expulsão de grupos vulneráveis. Enquanto muitos seriam contrários à "gentrificação", poucos se oporiam ao "renascimento urbano". É importante, portanto, explorar as formas pelas quais o Estado, como o defensor do bem público, legitima o processo. 
Em vista disso, se as cidades brasileiras trazem divergências com relação à concepção original do conceito, os próprios debates nos centros originadores da teoria da gentrificação têm detectado a necessidade de reformulação teórica para compreender a evolução do processo tanto nos casos tradicionais, quanto nas novas geografias da gentrificação. Tentando responder a esta evolução da gentrificação, Hackworth e Smith (2001) desenvolveram uma teoria sobre a mutação do processo identificando fases (waves) de transformação. A primeira fase (anterior a 1973) é caracterizada pela pequena intervenção estatal e gentrificação esporádica, dispersa e liderada por novos moradores em bairros na região nordeste dos Estados Unidos e Europa ocidental. Ou seja, essa primeira fase relaciona-se à concepção original e mais restritiva do conceito. Enquanto a recessão econômica da década de 1970 abriu caminho para investidores comprarem propriedades urbanas a preços baixos, é na segunda fase (iniciada na década de 1980) que processos de gentrificação são consolidados e intensificados, resultando em formas violentas de repressão ou na cidade revanchista (Smith, 1996). Nesse período, o processo de gentrificação é expandido espacialmente para novas e pequenas cidades, uma vez que ele está conectado com a reestruturação política e econômica global do neoliberalismo, como será detalhado na próxima parte deste artigo. Enquanto a crise econômica do começo da década de 1990 diminui o ritmo do processo nos casos tradicionais, a terceira fase representa sua intensificação e a apropriação como estratégia de novos produtos imobiliários em localizações já fora dos bairros adjacentes aos centros urbanos. É nesse período que a gentrificação assume novas formas e perde sua relação direta com a reversão do processo de suburbanização para incluir diferentes geografias de investimento e desinvestimento, materializada não somente na expulsão de moradores vulneráveis, mas também em grandes projetos para a produção, consumo e entretenimento. A gentrificação pós-1990 inclui agentes imobiliários maiores e mais diversos, direcionando vultosos investimentos para projetos de grande porte e em áreas mais distantes, incluindo novas construções e contando com o apoio cada vez maior do Estado para compensar os riscos envolvidos nesse novo padrão de gentrificação. Justificada pelo Estado para gerar empregos, impostos e recursos por meio do turismo, o processo de gentrificação tornou-se um fim em si mesmo, um objetivo a ser atingido. Nesse contexto, é possível concordar com Smith (2002) que a gentrificação é a principal política do urbanismo neoliberal e é a partir desta perspectiva que aquelas divergências nos casos brasileiros podem ser resolvidas.

\section{Gentrificação global e urbanismo neoliberal}

A gentrificação encontrada nas cidades brasileiras, portanto, não pode ser compreendida por meio da definição clássica do conceito relacionada à reversão do processo de suburbanização, com iniciativas pontuais de reforma de unidades residenciais, em edifícios históricos e em bairros centrais por grupos de classe média e alta. Os casos brasileiros, assim como aqueles identificados na China (He, 2007), Índia (Harris, 2008) e mesmo contemporaneamente nos países originais da teoria, pulam as fases iniciais 
para refletir as novas dimensões do processo que atinge escalas globais com a expansão do urbanismo neoliberal. Por um lado, é importante mencionar que as máquinas de crescimento urbano nos Estados Unidos prenunciavam muitos dos elementos do urbanismo neoliberal já na década de 1960 (Hall, 2002; Logan e Molotch, 1987). Por outro, o neoliberalismo transformará o que são experiências locais em uma agenda de desenvolvimento urbano divulgada mundialmente.

De forma geral, o neoliberalismo é baseado na teoria de que mercados livres, abertos e competitivos são o melhor mecanismo para o desenvolvimento econômico e equilíbrio institucional (Harvey, 2007). Enquanto a mobilidade de capital, produtos e pessoas, gerada pela globalização neoliberal, poderia significar a aniquilação do espaço, a intensificação da competição econômica - agora em escala global significou que o capital tornou-se muito mais sensível em relação às vantagens locacionais, não somente em termos dos meios materiais de produção, mas também em relação à divisão internacional do trabalho. Nesse contexto, não somente as políticas neoliberais afetaram as cidades, mas também as cidades (ou o espaço) tornaram-se a base a partir da qual o neoliberalismo está evoluindo, em especial por meio da implantação de regimes pró-capital em estruturas locais (Brenner e Theodore, 2002). A cidade neoliberal é uma cidade empresarial, planejada e governada por agências e instituições de caráter misto e operacionalizadas via parcerias público-privadas. Portanto, o Estado, na forma de governos locais, torna-se um membro ativo da produção capitalista e não apenas um regulador do mercado e agente da reprodução social. A cidade neoliberal também é uma cidade competitiva, focada em índices de crescimento econômico e, portanto, em atrair investimentos com a criação de um ambiente favorável aos negócios (good business climate) e promoção da qualidade de vida para os membros dessas economias, i.e., os usos e usuários "corretos" para o novo sistema econômico (Harvey, 1989c). Existe um processo de destruição criativa do espaço no qual os antigos arranjos socioespaciais tiveram que ser desmantelados para a construção do novo ajuste espacial (spatial fix) do neoliberalismo.

Nesse contexto, a gentrificação torna-se uma importante política pública, como estratégia local de curto prazo para aumentar a competitividade urbana (Hackworth, 2006). Ao remover usos antigos (como indústria e moradia de grupos empobrecidos), a gentrificação abre espaço para usos mais lucrativos para a economia neoliberal (por exemplo, serviços e comércios de ponta e desenvolvimentos imobiliários para atração de grupos de renda média-alta). Na sua fase atual, portanto, a expansão horizontal da gentrificação está relacionada a mudanças na divisão internacional do trabalho, valorização de novas atividades econômicas, expansão de mercados financeiros e políticas neoliberais que vão além de cidades globais de países centrais para incluir cidades periféricas que se transformaram em frentes de expansão do capital global, como Mumbai e São Paulo. Por outro lado, na sua expansão vertical, mudanças nas políticas urbanas e a promoção de cidades em um cenário de competição por investimentos resulta na identificação de processos de gentrificação em cidades heterogêneas, muitas vezes não incluídas nos grandes circuitos do capital global e, deste modo, atingindo não somente Nova York e São Paulo, mas 
também cidades menores nos Estados Unidos e Brasil. A globalização da gentrificação está ligada, portanto, ao urbanismo neoliberal tanto no surgimento de políticas competitivas pró-capital - considerando a cidade em si como um agente econômico - quanto ao refletir os padrões de investimento e desinvestimento em usos específicos do solo urbano, valorizando atividades que interessam à nova economia neoliberal (Smith, 2002). Gentrificação, nesse sentido, é um importante instrumento analítico que conecta os grandes ciclos de acumulação de capital com o contexto local de desenvolvimento urbano desigual.

Por outro lado, com os desenvolvimentos tecnológicos, dos meios de comunicação e a influência de elites e profissionais transnacionais, padrões de consumo são reproduzidos nas cidades mais diversas de sua origem. Portanto, também é importante compreender o processo de socialização do urbanismo neoliberal no qual a promoção de novos valores é tão importante quanto seus aspectos mais materiais (Miraftab, 2009). Com a integração da cultura na produção de mercadorias como parte fundamental desse novo sistema de acumulação, o que é hoje chamado de pós-modernismo responde às críticas sociais contra o sistema keynesiano-fordista ao exigir mais flexibilidade, liberdade pessoal e respeito às identidades múltiplas de sujeitos e lugares (Harvey, 1989a; Jameson, 1991). Dessa forma, ao promover uma rede de ideologias que importam não só modelos político-econômicos, mas também padrões de consumo e modos de vida, o urbanismo neoliberal expande processos de gentrificação como padrões de se fazer e viver o espaço urbano. Na criação destrutiva da cidade moderna-industrial, o pós-modernismo teve um papel fundamental na reestruturação político-econômica ao ser transformado em uma forma de "inovação estética e experimental que serve de base para a acumulação flexível" (Clarke, 2006, p. 37). ${ }^{4}$ Isso não quer dizer que qualquer iniciativa pós-moderna esteja integrada às estratégias de acumulação. Entretanto, mesmo com a renovada sensibilidade para a história urbana e elementos vernaculares, a arquitetura pós-moderna pode significar pastiches, projetos de restauração e áreas de turismo e entretenimento gentrificados. Além disso, a própria proeminência de edifícios-sede de grandes corporações e residenciais luxuosos como símbolos de vanguarda arquitetônica demonstra a apropriação da estética pelo capital contemporâneo. Na escala urbana, por outro lado, o pós-modernismo significou o fim da visão compreensiva e abrangente das cidades e a emergência do planejamento estratégico e fragmentado de áreas urbanas como tática de promoção de imagens competitivas e elementos distintivos, utilizando também de identidades socioespaciais para a atração de usos e usuários solventes. Portanto, o pós-modernismo pode promover a gentrificação ao expulsar grupos sociais e usos que não devem/podem participar dessa imagem competitiva ou não têm os recursos - financeiros ou sociais - que possibilitem sua permanência neste novo lugar.

A promoção de projetos de redesenvolvimento similares - que podem incluir ou não processos de gentrificação - nas cidades mais diversas e espalhadas por todo o mundo não responde simplesmente a uma evolução das formas arquitetônicas e urbanísticas. Essa homogeneizacão também é um efeito político-econômico da transformação do sistema capitalista. Enquanto a cultura foi integrada como 
estratégia de acumulação econômica, a promoção de um estilo da gentrificação (Zukin, 1987) transforma sua aceitação mais fácil ao identificá-la como pura expressividade da evolução estética e não como estratégia intensificadora do urbanismo desigual. É nesse sentido que é possível compreender que a arquitetura icônica e assinaturas de starchitects transformaram-se em verdadeiras estratégias de desenvolvimento urbano uma vez que:

Enquanto por séculos a qualidade do ambiente urbano foi um resultado do crescimento econômico das cidades, hoje em dia a qualidade do espaço urbano tornou-se um pré-requisito para o desenvolvimento econômico das cidades; e o desenho urbano tomou um papel proeminente como uma forma de desenvolvimento econômico. (Gospodini in Sklair, 2005 , p. 298 $)^{5}$

Portanto, a promoção de projetos e estilos globais é altamente valorizada social e economicamente tanto em cidades globais quanto em cidades periféricas, como estratégia de crescimento econômico e símbolo de status.

É nesses contextos que a gentrificação pode ser compreendida como um fenômeno global a ser identificado localmente por meio de três dimensões fundamentais:

1) Produção do espaço gentrificável: como mencionado, para que a gentrificação ocorra, deve existir uma diferença entre a extração de mais-valias obtida com os usos atuais do espaço e um potencial de extração de mais-valia por meio da mudança de usos e usuários. A principal motivação para a gentrificação é a possibilidade de extração de mais-valias urbanas através do redesenvolvimento, i.e., acabar com aquela diferença entre mais-valias atuais e potenciais (gap imobiliário [Smith 2010b]). Ainda assim, a gentrificação está ligada a um período histórico específico que a diferencia de outros processos de produção do espaço capitalista. Ou seja, a gentrificação deve ser entendida dentro do contexto de expansão de políticas neoliberais, urbanismo competitivo e a valorização de atividades do setor de comércio e serviço de ponta que têm impactos na força de trabalho e na economia local. Portanto, a destruição criativa que a gentrificação abarca localiza sistemas estruturais do capitalismo contemporâneo (capitalismo neoliberal) na produção desigual do espaço (microcontexto urbano).

\section{2) Elitização social com a expulsão de grupos} vulneráveis: no conflito entre usos atuais e usos mais rentáveis, a gentrificação implica a elitização social, ou seja, um grupo imigrante com padrões socioeconômicos mais valorizados do que na atual configuração socioespacial. Nesse processo, existe a expulsão da população de mais baixa renda e dos usos que não interessam ao novo modelo de ocupação do espaço. Portanto, a diferença na extração de mais-valias antes e depois do redesenvolvimento pode estar relacionada a usos mais valorizados, população de renda mais alta e padrões de consumo mais conectados à imagem idealizada de desenvolvimento urbano. Por outro lado, os usos e usuários anteriores, pouco valorizados pelo sistema atual, são expulsos direta ou indiretamente, por projetos de redesenvolvimento, renovações ou novas construções, pelo desvio de recursos de políticas sociais, pelo aumento do preço de aluguéis e propriedades, pela diminuição do mercado de unidades acessíveis a esses grupos, por pressão para a venda de suas propriedades e transformações na vida local 
em efeitos multiplicadores que também podem levar à expulsão, como a mudança de vizinhos, aumento do tráfego de veículos e verticalização de lotes adjacentes (Marcuse, 1986).

3) Transformação na paisagem construída: seja através de projetos formais de redesenvolvimento ou iniciativas individuais, a gentrificação é acompanhada de transformações na paisagem construída através dos investimentos em infraestrutura urbana, renovações, novas construções e usos. Ao perceber as potencialidades da gentrificação como estratégia de desenvolvimento econômico, empreendedores imobiliários, agentes públicos, profissionais de marketing e mesmo arquitetos capturam os aspectos mais visíveis da gentrificação para vender uma imagem atraente de cidades e bairros urbanos (Zukin, 1987). Se, por um lado, existe uma relação forte entre gentrificação e arquitetura e urbanismo pós-modernos, por outro, transformações físicas também estão relacionadas à construção de um novo arranjo espacial (spatial fix) para o desenvolvimento neoliberal, com uma nova configuração de áreas de produção, consumo e reprodução social. Portanto, mudanças do espaço físico podem ser indicadores de padrões de investimento e desinvestimento, apontando inclusive para transformações socioeconômicas e expulsão.

Dessa forma, temos uma concepção abrangente sobre a gentrificação contemporânea, alicercada por explicações acerca da produção e do consumo do processo e identificada por meio de três dimensões fundamentais que estão presentes em todos os casos. Por outro lado, esses fatores não explicam as diferentes geografias de investimento e desinvestimento nem são capazes de explicar por que algumas áreas são gentrificadas e outras não. Portanto, o processo ainda assume diferentes formas dependendo das condições de cada caso, i.e., as dimensões contingentes ou estruturas mediadoras do processo. É nesse sentido que podemos inserir a recente demanda pelo estudo das "geografias da gentrificação" (Lees, 2000), uma vez que em uma mesma cidade o processo de gentrificação não é completamente homogêneo (Butler e Robson, 2010; Hackworth e Smith, 2001). Diferentes mercados imobiliários, influência política, limites institucionais como legislação de uso do solo, formas de combater processos de expulsão, influência de organização locais e interesses privados podem direcionar o processo e fazer com que a gentrificação assuma formas específicas. É a partir desse modelo analítico de gentrificação que a experiência das operações urbanas consorciadas pode ser explorada, como será demonstrado a seguir.

\section{Operações urbanas em São Paulo: diálogos locais e globais}

Operações urbanas são projetos de redesenvolvimento urbano de caráter misto, unindo políticas de uso do solo e instrumentos financeiros para promover transformações urbanísticas por meio de capitais públicos e privados. É importante salientar que o termo significa tanto a definição da política pública quanto o estabelecimento de um projeto urbanístico específico para o redesenvolvimento de uma área urbana. Isso significa que, embora existam parâmetros gerais para o funcionamento de uma operação urbana (definidos nacionalmente no Estatuto 
da Cidade e localmente nos planos diretores), cada projeto contém elementos particulares e contextuais, constituindo não somente um lugar próprio (uma geografia urbana), mas também parâmetros urbanísticos distintos para cada experiência. Portanto, o instrumento reforça 0 entendimento da gentrificação através do diálogo entre dimensões fundamentais e contingentes do processo. Por outro lado, embora o modelo analítico sobre gentrificação possa ser generalizado, os achados empíricos sobre as operações urbanas em geral, bem como de cada projeto de operação urbana em específico, podem não o ser. É dessa forma que esta análise considera os elementos comuns às operações urbanas, fazendo referências às suas diferentes experiências na cidade de São Paulo para demonstrar a influência das estruturas mediadoras no processo.

Em termos da origem do instrumento, embora a primeira menção ao termo tenha sido feita na década de 1970 em um documento sobre o planejamento da região metropolitana de São Paulo (Costa, 1976), foi somente nos estudos para o plano diretor de 1985 que as operações urbanas foram definidas formalmente como um instrumento para promover transformações urbanísticas e prover infraestrutura e serviços públicos, incluindo habitação social (Sempla, 1985b). Considerando a necessidade de direcionamento do desenvolvimento urbano, em meio à constatação do "caos" que a cidade enfrentava nos anos 1980, a falta de recursos públicos para promover essas transformações foi um estímulo para se pensar em novas formas de financiamento desses projetos, como será mencionado a seguir. Além disso, os documentos de estudos para o plano diretor de 1985 justificam a criação das operações urbanas no contexto internacional de reestruturação urbanística:

[...] os estudos de planejamento urbano desenvolvidos nos últimos dez anos à luz da experiência internacional indicam que para 0 atendimento destes objetivos [de transformação urbanística] será de fundamental importância a implementação de uma categoria de empreendimento público designado por "operação urbana". (Sempla, 1985a, n. p.)

É sem surpresa, portanto, que durante as entrevistas com agentes promotores do instrumento (incluindo planejadores urbanos e políticos eleitos) experiências internacionais foram citadas como referências, principalmente Paris - considerada como a primeira iniciativa de venda de potencial construtivo -, e Nova York - em especial o Battery Park, como caso de sucesso de novas estratégias de desenvolvimento urbano que utilizam de parcerias público-privadas. Esse processo de aprendizagem com experiências internacionais não é original do caso das operações urbanas uma vez que a própria formação dos corpos técnicos de planejamento urbano no Brasil demonstra tanto o treinamento em outros países, quanto os diálogos com órgãos técnicos desses lugares já em sua origem. Entretanto, é importante especificar que, durante o momento de formulação das operações urbanas, o urbanismo neoliberal era estimulado não só como estratégia para recuperar a competitividade econômica em países centrais, mas também divulgado por órgãos multilaterais como "boas práticas" de gestão pública em países periféricos que enfrentavam crises econômicas, como o Brasil. Portanto, existe um duplo processo: um novo modelo de planejamento urbano estava em 
elaboração internacionalmente enquanto elites locais (políticas e intelectuais, no caso) tornaram-se aprendizes e condutoras de modelos de extração de mais-valia urbana inspirados nessas experiências internacionais, como no caso das operações urbanas.

Um segundo aspecto importante do instrumento é que ele sempre esteve associado diretamente com a provisão de infraestrutura pública, incluindo habitação social. Nesse sentido, a primeira operação urbana de São Paulo foi desenvolvida pela administração Luiza Erundina (1989-1993), que já utilizava outro instrumento de parceria público-privada para a provisão de habitação popular - as operações interligadas desenvolvidas durante o período do governo Jânio Quadros (1986-1989) e posteriormente declaradas inconstitucionais. Todavia, na primeira experiência com o instrumento da operação urbana, o foco foi no redesenvolvimento do centro histórico com a Operação Urbana Anhangabaú (Lei Municipal 11.090/1991). Mesmo que esse não seja considerado um caso de sucesso pelos informantes desta pesquisa, considerando a pouca transformação urbanística da área, essa administração continuou a explorar a possibilidade de operações urbanas em áreas de assentamentos informais (como nos estudos para a Operação Urbana Paraisópolis [Sempla, 1985b]), ainda focando na provisão de equipamentos públicos e habitação social. Entretanto, em administrações seguintes de inclinação ideológica mais conservadora, o instrumento foi redirecionado, abandonando o caráter inicial de provisão de infraestrutura social para passar a promover melhoramentos - em especial no sistema viário - de áreas já atrativas para o mercado imobiliário. Esse foi o caso com a experiência mais famosa e controversa de operação urbana em São Paulo até o momento, a Operação Urbana Faria Lima, criada pela administração Paulo Maluf em 1995 (Lei Municipal 11.732/1995). Além do interesse do próprio prefeito no redesenvolvimento local, ${ }^{6}$ as polêmicas geradas pelo projeto levaram à instauração de uma Comissão Parlamentar de Inquérito na Câmara de Vereadores que encontrou irregularidades em construções e no uso dos recursos, finalmente recomendando a transformação da legislação para o real atendimento do objetivo de provisão de infraestrutura social. ${ }^{7}$ Entretanto, o caso foi considerado de extremo sucesso pelos informantes do mercado imobiliário, em especial por causa do intenso processo de investimento que levou com que essa área hoje seja considerada a localização de negócios mais valorizadas socialmente em São Paulo e um dos metros quadrados mais caros da cidade.

Nesse sentido, operações urbanas também foram caracterizadas pela própria Prefeitura de São Paulo como um instrumento para restaurar a valorização imobiliária de uma área. ${ }^{8}$ Para o estabelecimento de uma operação urbana, existe a definição de um perímetro para sua implantação. 0 perímetro, segundo a caracterização da necessidade de redesenvolvimento, significa que essa área é considerada deficiente em algum aspecto urbanístico. Para promover sua transformação, 0 principal funcionamento do instrumento prevê a atração de investimentos do mercado imobiliário para o perímetro de atuação por meio de consórcios público-privados, associando o redesenvolvimento à infraestrutura urbanística. Segundo os planejadores urbanos entrevistados, as operações urbanas em São Paulo foram concebidas de acordo com a lógica de 
que as obras financiadas pelo poder público seriam compensadas pela atração de novos empreendimentos imobiliários, localização de empresas, criação de empregos e geração de impostos locais, entre outros. Portanto, além de ser uma política urbana que atua no espaço de forma fragmentada (com a definição do perímetro) e focada na promoção do espaço para atração da iniciativa privada (uma política urbana pró-capital), existe a identificação de uma geografia de desinvestimento que receberá investimentos públicos e privados para a valorização imobiliária. Nesse sentido, a designação de uma operação urbana leva à percepção de uma diferença entre as mais-valias acumuladas com os usos atuais e as mais-valias a serem acumulados com o uso "melhor e mais adequado" do espaço (definido de acordo com o plano urbanístico de cada operação). A formação dessa diferença é realizada pelo próprio Estado ao modificar os parâmetros urbanísticos da área, possibilitando o redesenvolvimento e a revalorização do perímetro. Portanto, a formação do espaço gentrificável, dimensão fundamental da gentrificação no urbanismo neoliberal, encontra-se claramente identificada no princípio de funcionamento de uma operação urbana.

Mais ainda, uma das principais justificavas para o instrumento da operação urbana é que os investimentos públicos seriam compensados principalmente por meio de pagamentos diretos aos cofres municipais pela venda de potencial construtivo. As operações urbanas são baseadas principalmente no instrumento da outorga onerosa do direito de construir. Isso significa que o mercado imobiliário pode construir mais do que o previsto originalmente no zoneamento urbanístico se o empreendedor pagar pelo solo criado. Essa possibilidade de venda e compra de potencial construtivo tem levado autores como Biderman et al. (2006) além de informantes desta pesquisa a caracterizar as operações urbanas como um instrumento de captura de mais-valia do solo urbano, ou seja, que recuperaria para os cofres públicos a valorização imobiliária criada pelos investimentos urbanísticos. Entretanto, essa recuperação não parece ser efetiva considerando que o pagamento por potencial construtivo é baseado em valores atuais e não em valores futuros de valorização das propriedades. Assim, em uma operação urbana, a localização, que é uma das variáveis mais importantes na definição do valor do solo urbano e suas edificações, será transformada através dos investimentos públicos e privados na área. Entretanto, segundo os técnicos envolvidos na concepção e desenvolvimento do instrumento, para atrair o mercado imobiliário seria necessário dar incentivos, como valores aproximadamente $30 \%$ abaixo do valor de metro quadrado de terreno atual. Portanto, não só as operações urbanas não têm capturado a valorização imobiliária da área, como também existe uma apropriação pelo mercado imobiliário dos efeitos positivos dos investimentos público-privados. Ou seja, o instrumento tem promovido a acumulação das mais-valias urbanas geradas pelo redesenvolvimento urbano pelo mercado imobiliário, confirmando ser uma política de produção do espaço pró-capital.

Além disso, em uma operação urbana, não só parâmetros construtivos como a taxa de ocupação e o índice de aproveitamento podem ser alterados, mas também usos e remembramentos, entre outros. Como a operação urbana é uma lei que se sobrepõe ao zoneamento 
local, isso significa que essa legislação é flexibilizada, i.e., essa área pode comportar tanto edificações e usos que seguem o zoneamento quanto novos empreendimentos que se adequem aos parâmetros da operação urbana. Usualmente sem estímulos para os usos atuais, eles não poderiam se valer diretamente dos benefícios a não ser para reformas que também requerem a compra dos títulos. De acordo com as entrevistas realizadas com funcionários das subprefeituras de São Paulo, esse é um dos grandes motivos da expulsão de moradores de áreas de operações urbanas, que não conseguem sequer entender o instrumento. Ao dar incentivos para novos empreendimentos e em muitos casos de maior porte, ${ }^{9}$ as operações urbanas promovem um novo modelo de ocupação e propriedade do solo urbano, requerendo a presença de grandes agentes imobiliários para adquirir e construir nos lotes de seu perímetro. Nesse sentido, a gentrificação pode ocorrer com a transformação de áreas comerciais, como através da expulsão de estabelecimentos de menor porte e usos residenciais na Operação Urbana Faria Lima; a transformação de parcelas industriais em grandes projetos imobiliários, como no setor Santo Amaro da Operação Urbana Água Espraiada; e a expulsão de moradores de áreas de investimento imobiliário através da verticalização. Dessa forma, os investimentos públicos e privados constituem uma real transformação do espaço construído por meio da valorização imobiliária e da expulsão dos usos e usuários não estimulados pelo plano urbanístico da operação urbana - conformando as outras duas dimensões fundamentais da gentrificação.

\section{A nacionalização das operações urbanas: instrumentos de promoção e resistência}

Em 2001, com a aprovação do Estatuto da Cidade (Lei Federal 10.257/2001), o instrumento foi formalizado como a principal política de redesenvolvimento urbano nacional. Ao adicionar a palavra "consórcio", a legislação deu ênfase à parceria público-privada como motor do redesenvolvimento urbano. A regulação federal das operações urbanas consorciadas no Estatuto da Cidade também legalizou a emissão dos títulos financeiros correspondentes à flexibilização dos parâmetros urbanísticos, já sendo utilizados na Operação Urbana Faria Lima. Os Cepacs (Certificados de Potencial Adicional de Construção) são títulos comercializados pela Bolsa de Valores de São Paulo em leilões públicos e que correspondem a uma determinada modificação de parâmetros urbanísticos. A equivalência entre o Cepac e a mudança do parâmetro urbanístico é determinada para cada operação urbana através de seu projeto urbanístico, podendo também ser relativa a setores dentro da mesma. Entretanto, uma vez comprados nos leilões públicos, os certificados podem ser comercializados em mercados secundários antes de serem utilizados em um lote dentro do perímetro da operação urbana. Enquanto ainda não existe uma legislação que imponha a vinculação do Cepac ao terreno em um período determinado - uma reclamação mencionada por vários agentes do mercado imobiliário durante as entrevistas -, os compradores podem 
"segurar" os títulos até sua valorização. Portanto, existe um mercado formal que pode especular com a produção do espaço dentro das operações urbanas, sendo essa uma atividade extremamente lucrativa. Confirmando tal fato, os informantes do mercado imobiliário afirmaram já terem sido abordados por terceiros tentando comercializar Cepacs com valores até cinco vezes maiores do que os vendidos durante o último leilão público da Operação Urbana Consorciada Água Espraiada (estabelecida pela Lei Municipal 13.260/2001).

Portanto, a comercialização de títulos de flexibilização de parâmetros urbanísticos significa a financialização do desenvolvimento urbano, conectando a produção do espaço em uma operação urbana a mercados financeiros globais. Desse modo, as operações urbanas estão diretamente inseridas no urbanismo neoliberal ao conjugar iniciativas público-privadas de valorização do solo urbano ao movimento global de capitais. Não é surpresa que, nesse contexto, as operações urbanas consideradas de maior sucesso em termos de transformação urbanística em São Paulo são aquelas localizadas próximo do novo centro de negócios da capital paulistana e as primeiras a utilizar leilões de Cepacs, em específico a Operação Urbana Faria Lima e a Operação Urbana Consorciada Água Espraiada. Por outro lado, em operações urbanas ou setores dentro dos seus perímetros onde o interesse do mercado imobiliário não é tão forte (como no caso do centro histórico de São Paulo), o instrumento não tem gerado transformações tão intensas, com estoques de potencial construtivo ainda altos. Assim, o interesse do mercado imobiliário é fundamental para o funcionamento do instrumento e este pode estar mediado por condições locais, como localização, acessibilidade, condições físicas (tamanho de lotes e condições das edificações), demanda por unidades de usos rentáveis, bem como o projeto urbanístico. Por outro lado, este interesse não é estático. 0 caso da Operação Urbana Água Branca (Lei Municipal 11.744/1995) demonstra que, apesar de o projeto não ter resultado em grandes transformações urbanísticas até recentemente, segundo os informantes essa é uma importante frente de expansão imobiliária atualmente. ${ }^{10}$

Finalmente, a concepção de operações urbanas tanto localmente quanto na sua inclusão no Estatuto da Cidade significa um confrontamento com a realidade do planejamento urbano brasileiro até aquele momento. Considerando a tradição modernista brasileira, em especial na formulação de planos diretores abrangentes a serem desenvolvidos e implantados por órgãos públicos, operações urbanas são uma forma de flexibilizar o planejamento urbano brasileiro ao conceder padrões urbanísticos diferenciados para certas áreas da cidade e parcerias público-privadas na condução do processo de redesenvolvimento. Nas reformas urbanísticas neoliberais, formas de planejamento urbano modernista foram consideradas obsoletas e obstáculos para o desenvolvimento econômico local (Watson, 2009), e a inspiração internacional para o instrumento já demonstra esse tipo de concepção sobre o planejamento urbano brasileiro. Por outro lado, aquele modelo de planejamento urbano modernista, com legislações de uso do solo burocráticas, rígidas e de longo prazo, também não garantiu a real aplicação destes instrumentos ou a integração socioespacial das cidades brasileiras, levando a deficiências de infraestrutura urbana, usos irregulares e ocupações informais (tanto de 
baixa, quanto de alta renda) (Maricato, 2002). Nesse contexto entende-se a justificativa por novos parâmetros urbanísticos tanto de cunho social, quanto mais voltado às estratégias de desenvolvimento econômico. Essa contradição reflete-se diretamente no Estatuto da Cidade.

0 Estatuto da Cidade reflete tanto a longa trajetória do Movimento da Reforma Urbana no Brasil e sua agenda de luta pelo direito à cidade (Osório, 2002; Saule Jr. e Rolnik, 2001), quanto os interesses do mercado imobiliário. Ao longo dos onze anos nos quais a lei foi discutida na Câmara dos Deputados, foi dentro da Comissão de Desenvolvimento Econômico, Indústria e Comércio (CDEIC) que a experiência da capital paulista com as operações urbanas foi integrada à lei. Examinando a tramitação do projeto, ${ }^{11}$ percebe-se que o Estatuto da Cidade foi duramente criticado por setores da economia brasileira, em especial empresas do mercado imobiliário e construção civil. A preocupação direcionava-se aos elementos mais progressistas da legislação. As atas da CDEIC denunciam o uso de "linguagem pejorativa" - como "especulação" e "exclusão" - e que além dos custos econômicos, a função social da propriedade interferia no livre mercado e no direito da propriedade individual estabelecida pela própria Constituição. Até aquele momento supostamente neutro, o instrumento poderia ser utilizado como uma forma de financiar infraestrutura pública e habitação popular ou promover um estímulo à especulação imobiliária, como demonstrado pela experiência de prefeitos de diferentes posições ideológicas em São Paulo (Maricato e Ferreira, 2002). Entretanto, considerando a filiação do relator final do Comitê ao mesmo partido do ex-prefeito Paulo Maluf, o teor das discussões nas atas das reuniões e os agradecimentos ao secretário de planejamento urbano de São Paulo no momento de implantação da Operação Urbana Faria Lima (Gilberto Kassab, posteriormente prefeito de São Paulo), é possível concluir que o instrumento vem ao encontro dos interesses daqueles grupos que protegiam o livre mercado e os direitos de propriedade individual diante da agenda da reforma urbana. Como mencionado por um ex-deputado federal da capital paulista, "Vamos ser claros, [a operação urbana] é um instrumento de uma sociedade capitalista (...), de uma inciativa privada forte; a visão de que a propriedade é um instrumento importante da realizaçao da sociedade... É isso. Se não, não sai" (em entrevista com a autora).

Portanto, é possível adicionar uma outra contradição a estas novas formas de planejamento urbano considerando que em realidades de grande desigualdade social, como São Paulo, planos compreensivos podem estabelecer prioridades universalistas e includentes (Leite e Somekh, 2009). Mesmo considerando que os planos modernos brasileiros transformaram-se em discurso e não levaram a uma real integração dos espaços e grupos urbanos (Maricato, 2002), o tratamento da cidade de forma fragmentária, particular e estratégica continua a reproduzir ou reforçar clivagens socioespaciais. Nas operações urbanas, este risco fica ainda mais claro considerando que os recursos obtidos com os Cepacs devem ser utilizados na realização de obras e projetos previstos no plano urbanístico da operação urbana, e esses estão contidos obrigatoriamente no perímetro da mesma. Por um lado, essa é uma garantia aos investimentos privados de que os recursos gastos na compra de Cepac serão reinvestidos 
na área, assegurando a valorização imobiliária. Por outro lado, isso significa, como já mencionado, que operações urbanas com maior interesse do mercado imobiliário terão mais investimento enquanto outras, menos atrativas, ou áreas da cidade excluídas dos perímetros desses projetos, continuarão a receber pouco investimento, em um ciclo que reforça os padrões de desenvolvimento urbano desigual. Portanto, existe uma tensão entre velhas e novas culturas de planejamento urbano que resulta em um instrumento urbanístico capaz de gerar uma grande transformação socioespacial da cidade sem impacto em mobilidade social ou na meIhoria da qualidade de vida para todos.

No entanto, é dentro do próprio sistema de planejamento urbano brasileiro que se encontram outros elementos mediadores que podem ser utilizados para resistir às operações urbanas. É importante mencionar que, ao contrário de muitos outros casos, incluindo cidades nos Estados Unidos e Inglaterra, o planejamento urbano no Brasil tem força de lei. Isso significa que não só planos diretores, mas também outras iniciativas públicas, como projetos e programas de intervenção, devem ser aprovados como legislação. É a partir de carências no cumprimento dessas leis que organizações locais e movimentos sociais têm encontrado formas de resistir às operações urbanas e remoções, recorrendo ao Poder Judiciário. Dessa forma, o sistema de justiça brasileiro pode ser mobilizado contra decisões de outras instituições públicas, fato que não se verifica naqueles países de casos tradicionais de gentrificação. É neste sentido que devemos entender o funcionamento do Ministério Público e da Defensoria Pública na defesa do direito urbanístico, em casos nos quais o Estado passa a ser réu, especialmente os municípios, uma vez que esses são a arena principal de planejamento urbano no país.

A Operação Urbana Consorciada Água Espraiada é ilustrativa. Por um lado, é importante mencionar que as associações de moradores dos bairros Vila Cordeiro e Brooklin conseguiram mobilizar o Ministério Público do Estado de São Paulo contra a Prefeitura de São Paulo ao identificaram intervenções no projeto que vão de encontro ao zoneamento Z1 (exclusivamente residencial) de quadras incluídas no perímetro da operação urbana. Nesse caso, por meio da mobilização destas organizações, a prefeitura assinou um Termo de Ajustamento de Conduta com o Ministério Público estadual. Entre outros, o termo impede as transposições sobre a Avenida Água Espraiada sem aprovação das associações, obriga a obstacularização de vias locais para impedir que o tráfego gerado pela operação urbana adentre os bairros e mantém os usos exclusivamente residenciais bem como as áreas verdes nas quadras dos bairros Vila Cordeiro e Brooklin Novo incluídas no perímetro do projeto. ${ }^{12}$

Por outro lado, a remoção da população de renda mais baixa da Operação Urbana Consorciada Água Espraiada também foi alvo de ações judiciais, em especial no caso da comunidade Jardim Edith. Enquanto desde o início da construção da avenida, antes da formalização da operação urbana, a comunidade já fosse alvo de processos violentos e arbitrários de remoção (Fix, 2001), com o estabelecimento do projeto urbanístico a área ocupada pela comunidade foi designada como uma Zona Especial de Interesse Social 1 (Zeis 1), ou seja, uma área já ocupada pela população de baixa renda e que há o interesse público na promoção de 
melhorias urbanísticas, regularização fundiária e/ou produção e manutenção de habitações de interesse social. Segundo informantes locais, o próprio estabelecimento da Zeis 1 no Jardim Edith já foi conturbado, considerando os interesses imobiliários da área localizada próxima ao novo centro de negócios da capital paulista, ao lado de projetos icônicos de arquitetura pós-moderna e do novo cartão postal da cidade, a Ponte Otavio Frias de Oliveira - mais uma vez confirmando o processo de transformação da paisagem construída que a gentrificação abarca. Por outro lado, a própria formalização do instrumento da operação urbana obriga o atendimento de qualquer parcela da população removida dentro do perímetro do projeto. Mesmo assim, a Prefeitura de São Paulo continuava removendo e demolindo habitações na comunidade, dando como alternativas de atendimento um valor monetário (o famoso cheque-despejo) ou a possibilidade de compra de uma unidade em conjunto habitacional construído fora do perímetro da operação urbana, na periferia da cidade. A associação de moradores acionou a Defensoria Pública que ingressou com uma ação judicial contra a prefeitura. Em 2008, com o parecer positivo do Ministério Público, o direito de permanência foi assegurado com a construção de unidades no próprio local. ${ }^{13} \mathrm{Em}$ que pesem o histórico e violento processo de remoção da comunidade, o processo judicial contra a própria prefeitura e o número reduzido de unidades construídas em relação à demanda local, em 2013 as famílias do Jardim Edith começaram a ocupar os prédios entregues em uma das esquinas mais valorizadas de São Paulo e da janela de seus apartamentos olham para a paisagem conformada pelo capital global em uma cidade na periferia do capitalismo.

\section{Considerações finais}

Como definido ao longo deste artigo, gentrificação é um processo de redesenvolvimento urbano que leva à elitização social e expulsão de grupos vulneráveis. Por um lado, ela é baseada no processo de criação destrutiva do espaço urbano para a promoção de um novo arranjo socioespacial que privilegia usos e usuários ligados à economia neoliberal. Por outro, processos de gentrificação estão baseados no consumo de estilos de vida, desenhos urbanos e projetos arquitetônicos apoiados em um novo padrão sociocultural pós-moderno. Entretanto, o processo leva à expulsão de usos e usuários que não interessam a esse novo arranjo de atividades de produção, consumo e reprodução social. Este artigo, no entanto, defende a necessidade de se contextualizar o processo de gentrificação. Partindo-se do pressuposto de que conceitos são categorias abstratas que podem não existir na realidade, mas auxiliar no seu entendimento, este artigo defende que nossas teorias sejam suficientemente flexíveis para acomodar dados empíricos que podem ser contextuais e específicos.

Esse é o caso da experiência com as operações urbanas em São Paulo. Se por um lado, as três dimensões fundamentais da gentrificação são facilmente identificadas na concepção do instrumento urbanístico, elas estão contextualizadas tanto na formalização da operação urbana em uma política urbana federal e municipal, quanto na conformação de um projeto específico. Os elementos básicos de funcionamento do instrumento expõem, nesse sentido, as dimensões fundamentais da gentrificação: a delimitação de um perímetro através 
da identificação de uma área que necessitaria de investimentos público e privados (produção do espaço gentrificável); a definição de usos e usuários a serem incentivados e estímulo à valorização imobiliária (elitização socioeconômica e possibilidade de expulsão de grupos vulneráveis), e canalização de investimentos público e privados através da venda de Cepacs, com mudança de parâmetros urbanísticos e utilização desses recursos em obras e projetos contidos no perímetro da operação urbana (transformação da paisagem construída). Por outro lado, existem dimensões contingentes do processo localmente que estão relacionadas também com a definição do projeto urbanístico em si, explicando as diferenças entre cada caso, sendo os de mais sucesso aqueles que levaram a intensas transformações socioespaciais. Portanto, se há forças estruturadoras globais que impulsionam e generalizam a gentrificação, também existem formas de dominação e resistência locais que caracterizam o processo.

Em conclusão, este modelo analítico considera que neoliberalismo e globalização, bem como modelos de planejamento urbano, arranjos público-privados e formas de resistência aos mesmos, são produzidos em múltiplos centros e periferias. Embora a gentrificação tenha sido generalizada com principal política do urbanismo neoliberal, a produção desigual do espaço e a gentrificação também são produzidas localmente, como é o caso das operações urbanas no Brasil. 0 que está em questão, portanto, não é o fato de que gentrificação é específica nas cidades brasileiras. Pelo contrário, a gentrificação é sempre específica e casos em cidades brasileiras podem ser tão diversos quanto casos naqueles contextos urbanos no qual a teoria foi originada

\section{Marina Toneli Siqueira}

Universidade de Illinois, Departamento de Planejamento Urbano e Políticas Públicas. Chicago, Estados Unidos.

marinasiq@yahoo.com.br 


\section{Notas}

$(*)$ A autora gostaria de agradecer a Capes/Fulbright pelo financiamento desta pesquisa.

(1) Para a análise das operações urbanas em São Paulo foram realizadas consultas a bibliotecas e arquivos, análise de dados secundários (em especial, censos e mercado imobiliário), entrevistas com 48 informantes (incluindo políticos eleitos, planejadores urbanos e funcionários de instituições da Prefeitura Municipal de São Paulo, agentes do mercado imobiliário, associações de moradores e residentes locais), além de visitas a campo.

(2) A tradução para o português foi realizada pela autora. No original em inglês, lê-se: se "one of the major 'leading edges' of contemporary metropolitan restructuring" (Hamnett, 1991, p. 174).

(3) O termo "revitalização" é usado entre aspas para enfatizar sua construção ideológica. Por um lado, esse tipo de analogia biologicista ignora os agentes responsáveis pelo processo de desinvestimento dos centros históricos brasileiros, i.e., a escolha deliberada pelo direcionamento de recursos públicos e privados para outras áreas. Por outro, esses projetos não identificam a vida conformada por usuários de renda mais baixa que movimentam o centro histórico seja através do transporte público ou das opções de moradia existentes na região. Esses projetos criam, desta forma, uma imagem desses lugares como "sem vida" ou "mortos", desconsiderando formas de apropriação do espaço que não seguem a cartilha prescritiva dos projetos de "revitalização", podendo gerar sua expulsão.

(4) No original em inglês, lê-se: "aesthetic innovation and experimentation to support flexible accumulation" (Clarke, 2006, p. 37). A tradução livre foi realizada pela autora.

(5) No original em inglês, lê-se: "While for centuries the quality of the urban environment has been un outcome of economic growth of cities, nowadays the quality of urban space has become a prerequisite for the economy development of cities; and urban design has undertaken an enhanced new role as a means of economic development" (Gospodini in Sklair, 2005, p. 298). A tradução livre foi realizada pela autora.

(6) É estimado que sob o nome de "investimentos", 85\% dos recursos públicos entre 1993 e 1994 (durante a prefeitura Paulo Maluf) foram concentrados na expansão da cidade no setor sudoeste com túneis e prolongamentos de avenidas (Rolnik, 1997). Esse processo foi reforçado ao designar operações urbanas neste setor da cidade.

(7) Mais informações sobre esta comissão disponíveis em http://www1.camara.sp.gov.br/comissao. asp?IDComissao=65\&Tipo=3. Acesso em: 25 março 2011.

(8) Já nos primeiros documentos do Sempla (1985a e 1985b), operações urbanas eram incluídas no rol de políticas imobiliárias. Essa caracterização das operações urbanas como instrumentos de restauração da valorização imobiliária esteve presente no site da Emurb até pelo menos 17 de outubro de 2010 (http://www.prefeitura.sp.gov.br/cidade/secretarias/infraestrutura/emurb/ operacoes_urbanas/index.php?p=813). Entretanto, em 4 de outubro de 2013 a página a qual este artigo faz referência não estava mais disponível online.

(9) Por exemplo, na Operação Urbana Faria Lima, existem diversos incentivos para a construção em lotes maiores do que $1.000 \mathrm{~m}^{2}$ e remembramento de lotes para atingir uma área igual ou maior do que $2.500 \mathrm{~m}^{2}$ (http://www.prefeitura.sp.gov.br/cidade/secretarias/desenvolvimento_ urbano/sp_urbanismo/operacoes_urbanas/faria_lima/index.php?p=19610. Acesso em: 17 abril 2010). 
(10) Por outro lado, o projeto urbanístico da Operação Urbana Água Branca está passando por revisões em 2013.

(11) Disponível em: http://www.camara.gov.br/internet/sileg/Prop_Detalhe.asp?id=65069. Acesso em: 27 março 2011.

(12) O Termo de Compromisso de Ajustamento de Conduta foi cedido pelo Ministério Público de São Paulo por meio de solicitação durante entrevista com promotores públicos estaduais.

(13) O parecer do Ministério Público de São Paulo foi cedido por meio de solicitação durante entrevista com promotores públicos estaduais.

\section{Referências}

ATKINSON, R. e BRIDGE, G. (orgs.). (2005). Gentrification in a global context: the new urban colonialism. Nova York, Routledge.

BIDERMAN, C.; SANDRONI, P. e SMOLKA, M. (2006). The case of Faria Lima in São Paulo. Disponível em: http://www.lincolninst.edu/pubs/1114_Large-scale-Urban-Interventions. Acesso em: 6 out 2011.

BIDOU-ZACHARIASEN, C. (org.). (2006). The volta à cidade: dos processos de gentrificação às políticas de "revitalização" dos centros urbanos. São Paulo, Annablume.

BRENNER, N. e THEODORE, N. (2002). "Cities and the geographies of 'actually existing neoliberalism'”. In: BRENNER, N. e THEODORE, N. (orgs.). Spaces of neoliberalism: urban restructuring in North America and Western Europe. Cambridge/Oxford, Blackwell.

BUTLER, T. e ROBSON, G. (2010). "Social capital, gentrification and neighborhood change in London: a comparison of three South London neighborhoods". In: LEES, L. et al. (orgs.). The Gentrification Reader. Nova York, Routledge.

CHERNOFF, M. (2010). "Social displacement in a renovating neighborhood's commercial district". In: BROWN-SARACINO, J. (org). The gentrification debates: a reader. Nova York, Routledge.

CLARKE, P. (2006). "The economic currency of architectural aesthetics". In: CUTHBERT, A. (org.). Designing cities: critical readings in urban design. Cambridge/Oxford, Blackwell.

COSTA, L. C. (1976). "Estrutura Urbana”. In: SÃO PAULO (Governo do Estado). O desafio metropolitano. São Paulo, SNM/Emplasa.

DAVIDSON, M. e LEES, L. (2010). New-build gentrification: its histories, trajectories, and critical geographies. Population, Space and Place. Hoboken, v. 16, n. 5, pp. 395-411.

FIX, M. (2001). Parceiros da exclusão. Duas histórias de construção de uma "Nova Cidade" em São Paulo: Faria Lima e Água Espraiada. São Paulo, Boitempo Editorial.

FRÚGOLI Jr., H. (2000). Centralidade em São Paulo: trajetórias, conflitos e negociações. São Paulo, Edusp. 
FRÚGOLI Jr., H. e SKLAIR, J. (2008). The Luz district in São Paulo: anthropological questions on the phenomenon of gentrification. Disponível em: http://sitemason. vanderbilt.edu/files/gO5Hfq/ FrugoliSklair.doc. Acesso em: 29 out 2010.

GLASS, R. (1989). Clichés of urban doom. Cambridge/Oxford, Blackwell.

(2010). “London: aspects of change”. In: LEES, L. et al. (orgs.). The Gentrification Reader. Nova York, Routledge. (Trabalho original publicado em 1964.)

GOTHAM, K. (2005). Tourism Gentrification: The Case of New Orleans' Vieux Carré (French Quarter). Urban Studies. Glasgow, v. 42, n. 7, pp. 1099-1121.

HACKWORTH, J. (2006). The Neoliberal City: Governance, Ideology, and Development in American Urbanism. Ithaca, Cornell University Press.

HACKWORTH, J. e SMITH, N. (2001). The changing state of gentrification. Tijdschrift voor Economische en Sociale Geografie. Hoboken, v. 22, n. 2, pp. 464-477.

HALL, P. (2002). Cities of Tomorrow. Cambridge/Oxford, Blackwell.

HAMNETT, C. (1991). The blind men and the elephant. Explanations of gentrification. Transactions of the Institute of British Geographers. Hoboken, v. 16, n. 2, pp. 173-189.

HARRIS, A. (2008). From London to Mumbai and back again: gentrification and public policy in comparative perspective. Urban Studies. Glasgow, v. 45, n. 12, pp. 2407-2428.

HARVEY, D. (1997). "Flexible accumulation through urbanization". In: AMIN, A. (org). Post-Fordism. A Reader. Cambridge/Oxford, Blackwell.

(1989a). The condition of postmodernity. Cambridge/Oxford, Blackwell.

(1989b). The urban experience. Baltimore, Johns Hopkins University Press.

(1989c). From managerialism to entrepreneurialism: the transformation in urban governance in late capitalism. Geografiska Annaler, Series B. Hoboken, v. 71, n. 1, pp. 3-17.

(2007). A brief history of neoliberalism. Oxford, Oxford University Press.

$\mathrm{HE}$, S. (2007). State-sponsored gentrification under market transition: the case of Shanghai. Urban Affairs Review. Thousand Oaks, v. 43, n. 2, pp. 171-198.

JACOBS, J. (1992). The death and life of great american cities. Nova York, Vintage Books. (Trabalho original publicado em 1961.)

JAMESON, F. (1991). Postmodernism or The cultural logic of late capitalism. Durham, Duke University Press.

LAMBERT, C. e BODDY, M. (2002). Transforming the city: post-recession gentrification and re-urbanisation. Disponível em: http://www.bris.ac.uk/sps/cnrpaperspdf/cnr6pap.pdf. Acesso em: 16 mar 2011.

LEES, L. (2000). A reappraisal of gentrification: towards a "geography of gentrification". Progress in Human Geography. Thousand Oaks, v. 24, n. 3, pp. 389-408.

LEES, L. e LEY, D. (2008). Introduction: Gentrification and public policy. Urban Studies. Glasgow, v. 45, n. 12 , pp. 2379-2384. 
LEITE, C. e SOMEKH, N. (2009). São Paulo: implementando a mudança urbana (1). Disponível em: http://www.vitruvius.com.br/revistas/read/minhacidade/09.105/1855. Acesso em: 30 out 2010.

LEITE, R. P. (2007). Contra-usos da cidade: lugares e espaço público na experiência urbana contemporânea. Campinas, Unicamp.

LOGAN, J. e MOLOTCH, H. (1987). Urban fortunes: the political economy of place. Berkley, University of California Press.

MARCUSE, P. (1986). Gentrification, abandonment, and displacement: connections, causes and policy responses. Journal of Urban and Contemporary Law. St. Louis, v. 28, pp. 195-240.

MARICATO, E. (2002). "As ideias fora do lugar e o lugar fora das ideias: planejamento urbano no Brasil". In: ARANTES, O.; VAINER, C. e MARICATO, E. A cidade do pensamento único: desmanchando consensos. Petrópolis, Vozes.

MIRAFTAB, F. (2009). Insurgent planning: situating radical planning in the Global South. Planning Theory. Thousand Oaks, v. 8, n. 1, pp. 32-50.

OSÓRIO, L. M. (org.). (2002). Estatuto da Cidade e reforma urbana: novas perspectivas para as cidades brasileiras. Porto Alegre, Sérgio Antonio Fabris Editor.

ROLNIK, R. (1997). A cidade e a lei. São Paulo, Studio Nobel/Fapesp.

RUBINO, S. (2005). "A curious blend? City revitalization, gentrification and commodification in Brazil". In: ATKINSON, R. e BRIDGE, G. (orgs.). Gentrification in a global context: the new urban colonialism. Nova York, Routledge.

SAULE Jr., N. e ROLNIK, R. (2001). Estatuto da Cidade: novos horizontes para a reforma urbana. São Paulo, Pólis.

SEMPLA (Prefeitura de São Paulo). (1985a). Plano Diretor - Dossiê Operações Urbanas, julho 1983 a janeiro 1985. São Paulo.

(1985b). Plano Diretor do Município de São Paulo 1985-2000. São Paulo.

SILVA, H. M. B. (coord.). (2006). Relatório da pesquisa: observatório do uso do solo e da gestão fundiária do centro de São Paulo. Disponível em: http://www.usp.br/fau/depprojeto/labhab/biblioteca/ produtos/observatorio_pcentro.pdf. Acesso: 5 mar 2013.

SKLAIR, L. (2005). The transnational capitalist class and contemporary architecture in globalizing cities. International Journal of Urban and Regional Research. Hoboken, v. 29, n. 3, pp. 485-500.

SMITH, N. (1996). The new urban frontier: gentrification and the revanchist city. Nova York, Routledge. (2002). New globalism, new urbanism: gentrification as global urban strategy. Antipode. Hoboken, v. 34, n. 3, pp. 429-450.

(2010a). "A short history of gentrification". In: BROWN-SARACINO, J. (org.). The gentrification debates: a reader. Nova York, Routledge. (Trabalho original publicado em 1982.)

(2010b). Towards a theory of gentrification: a back to the city movement by capital, not people. In: LEES, L. et al (org.). The gentrification reader. Nova York, Routledge. 
VARGAS, H. e CASTILHO, A. (orgs.). (2005). Intervenções em centros urbanos: objetivos, estratégias e resultados. São Paulo, Manole.

VILLAÇA, F. (1998). Espaço intra-urbano no Brasil. São Paulo, Studio Nobel/Fapesp.

WATSON, V. (2009). Seeing from the South: Refocusing urban planning on the globe's central urban issues. Urban Studies. Glasgow, v. 46, n. 11, pp. 2259-2275.

ZUKIN, S. (1987). Gentrification: culture and capital in the urban core. Annual Review of Sociology. Palo Alto, v. 13, pp. 129-147.

Texto recebido em 15/nov/2013

Texto aprovado em 13/fev/2014 
